\title{
Ameliyathanede Ergonomik Faktörler ve Çalışan Güvenliği
}

\section{Ergonomic Factors and Staff Safety in the Operating Room}

\author{
Esma ÖZŞAKER ${ }^{\mathrm{a}}$
}

ÖZ Ameliyathanede sağlı çalışanları için birçok tehlike alanı mevcuttur. Çalışan güvenliğini etkileyen faktörlerden biri de ergonomik faktörlerdir. Sağlık çalışanları, ameliyathanede fiziksel, bilişsel ve örgütsel ergonomik risk faktörlerine maruz kalabilirler. Ameliyathanede ergonomik koşullar çalışanların sağlığını, iş doyumunu ve performansı etkiler. Bu makalenin amacı, ameliyathane ortamında ergonomik faktörlerin çalışan güvenliğine olan etkilerini literatür ışı̆̆ında incelemektir. Bu kapsamda ameliyathanede ergonomik tasarımın, kullanılan araç-gereçlerin çalışan güvenliğine olan etkilerine ve ergonomik risk faktörlerine yönelik önerilere yer verildi.

Anahtar sözcükler: Ergonomi, ameliyathane, güvenlik, çalışan güvenliği

\begin{abstract}
There are many danger areas for health professionals in the operating room. One of the factors that affect the safety of staff are ergonomic factors. Operating room's staff can be exposed to physical, cognitive and organizational ergonomic risk factors. Ergonomic conditions in operating rooms effects staff's health, job satisfaction and performance. The purpose of the article is to examine the potential impact of the ergonomic factors on staff safety in the operating room in the light of the literature. In this context, the impact of ergonomic design in the operating room and the tools used on the staff safety and recommendations for the ergonomic risk factors was addressed.
\end{abstract}

Keywords: Ergonomics, Operating room, Safety, Staff safety

\section{Giriş}

İnsan ve çalışma ortamı arasındaki etkileşim olarak da ifade edilen ergonomi "insan faktörleri" olarak da bilinen ve çalışma ortamında insanı merkeze alan bir tasarım bilimidir (1-2). Ergonomi, insanların ihtiyaçları, yetenekleri ve sinırlılıkları bakımından insanlarla etkileşimde olan her şeyin/nesnenin insanların ihtiyaçları, bilgi ve yetenekleri ile uyum içinde olmasını sağlar (2-3).

Çalışanın sağlığı ile çalışma ortamı arasında iki yönlü bir etkileşim vardır. Çalışma koşulları çalışanın sağlığını, sağlık da bireyin çalışma kapasitesini etkilemektedir. Ameliyathaneler özel bilgi, beceri ve eğitim gerektiren çeşitli tıbbi malzeme ve ekipmanın yanı sıra, yeni teknolojilerle donatılmış stresli ve karmaşık çalışma alanlarıdır (3).

Çalışma ortamında sağlığ 1 ve güvenliğ $i$ etkileyen unsurlardan biri de ergonomik risk faktörleridir (3-4). Yeni teknolojiler ve ürünler ortaya çıktıkça, ergonomi sağlık sektöründe giderek daha önemli bir unsur haline gelmiştir (56). Ergonomiyle ilgili sorunların özelliklerini anlamak, etkin müdahaleye yönelik gerekli tedbir- erin alınması bakımından önemlidir (6). Multidisipliner bir alan olan ergonomi 'Uluslararası Ergonomi Birimi' tarafından fiziksel, bilişsel ve örgütsel olmak üzere üç alt bileşende tanımlanmaktadır $(2,4)$. Sağlık çalışanları ameliyathanede ergonomik risk faktörlerine maruz kalabilmektedirler (3).

\section{Ameliyathane Ortamında Karşılaşılan Fiziksel Ergonomik Risk Faktörleri}

Çalışanların anatomik, antropometrik, fizyolojik ve biyomekanik özellikleri, çalışma sırasındaki duruşları, taşıma/kaldırma eylemleri, tekrarlanan hareketler, fiziksel iş yükü, fiziksel ergonominin alanıdır $(1,2,4)$. Ameliyathane ortamında karş1laşılan fiziksel ergonomik risk faktörleri arasında; hasta/malzemeleri taşıma ve kaldırma, pozisyon (duruş), fiziksel ortam ve kullanılan araç/gereçler yer almaktadır $(3,7,8)$. Kaygan ve islak zeminler, pürüzlü zemin yüzeyleri, dağınık ve düzensiz odalar, dar geçitler ve özellikle akşam vardiyalarında yetersiz aydınlatma, çalışma ortamına bağlı fiziksel ergonomik risk faktörleridir (3). Hastaları

Geliş Tarihi/Received:201-12-2017/ Kabul Tarihi/Accepted:27-03-2018

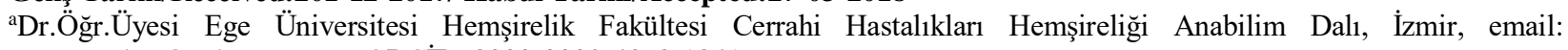
esmaozseker@yahoo.com, ORCID: 0000-0002-4878-1841 
ve ağır yükleri; tek başına taşıma/kaldırma, vardiya başına birden fazla kaldırma, elle taşıma, obez ve bilinçsiz hastaları taşıma, vücut mekaniklerine dikkat etmeden taşıma ve kaldırma, omuz yüksekliğinin üzerinde ve diz yüksekliğinin altında çalışma, ağır aletleri uzun süre vücuttan uzakta tutma, aşırı çaba uygulama, tepsiler, monitörler, hastalar gibi ağır yükleri itme, çekme, indirme gibi uygulamalar taşıma ve kaldırmaya bağlı fiziksel ergonomik risk faktörleridir $(3,7,8)$. Ergonomik olmayan, kırık/bozuk araç-gereç kullanma ve röntgen kullanılan ameliyatlarda kurşun önlük giyilmesi araç gereçle ilişkili fiziksel ergonomik risk faktörlerini oluşturmaktadır (3).

Ameliyathanede sağlık personelinin yanlış vücut biyomekaniği kullanması, tekrarlanan hareketler, sırtın hiperekstansiyonu / fleksiyonu, uygun olmayan postür, uzun süre ayakta kalma, uzun süre aynı pozisyonda kalma, güç gerektiren görevler, ameliyathane ekipmanına / arabalara çarpma pozisyona bağlı fiziksel ergonomik risk faktörleridir (3,6,7,9). Abdullahzade ve ark. (2016) tarafindan ameliyathane hemşirelerinin çalışma pozisyonlarına ilişkin yapılan çalışmada; çalışma ortamında hemşirelerin çalışma postürleri hızlı vücut değerlendirme yöntemi (Rapid Entire Body Assessment - REBA) ile değerlendirilmiş ve REBA skor ortalaması 7.7 bulunmuş. Yüksek REBA puanı, çalışma koşullarının hatalı olduğunu ve hemşirelerin iş sırasındaki duruşlarının sürdürülmesinin zor olduğunu ortaya koymaktadır. $\mathrm{Bu}$ sonuç ameliyathane hemşirelerinin genelde yüksek risk taşıdığını göstermektedir (10). Voss ve ark. (2017) tarafindan ameliyatlarda ergonomik tehlikelere ilişkin yapılan bir çalışmada çalışanların pozisyonlarının ergonomik olmadığı saptanmıştır (11). Matern ve Koneczny (2007) genel çalışma pozisyonlarının, cerrahların \%84'ü tarafindan rahatsız ya da ağrı verici olduğunu belirtmişlerdir (5). Albayrak ve ark. (2007) ise cerrahların ameliyata çok yoğunlaştıklarından, duruşlarını ihmal etme eğiliminde olduklarını ve bu nedenle vücut desteğine ihtiyacın arttığını bildirmişlerdir (12).

Robot destekli cerrahinin endoskopik cerrahiden daha rahat olduğu düşünülse de çalışmalar mevcut konsol kurulumunda ergonomik açıkların kaldığını göstermiştir. Da Vinci konsolun optimum kol dayama yüksekliğinin kısa ve çok uzun boylu kişiler için ayar aralığının dışında olduğu saptanmıştır (13). El Ata ve ark. (2016) tarafindan ameliyathane hemşirelerinde işe bağlı kas iskelet sistemi hastalıklarının (İBKİSH) incelendiği çalışmada, ameliyathane hemşirelerinde saptanan mesleki risk faktörleri sirasıyla boynu fleksiyonda tutarak çalışma (\%95), uygun olmayan postür (\%90.2), el ve bileğin deviasyonu (\%84.8), el ve bileğin tekrarlayan hareketi (\%84.8), dört saat ve üzeri ayakta durma $(\% 81)$, ağır nesneleri hareket ettirme/kaldırma (\%64.7), ağır nesneleri itme/çekme (\%64.1) ve kolu uzatarak çalışma (\%26.1) olduğu saptanmıştır. Ameliyathane hemşirelerindeki mevcut mesleki risk faktörleri ile kas iskelet sistemi rahatsızlıkları arasında anlamlı ilişki saptanmıştır (9).

Matern ve Koneczny (2007) ameliyathanedeki güvenlik, tehlikeler ve ergonomi konusunda yaptıkları çalışmada; cerrahların \%78'inin ameliyathane masalarının ayarlanabilir olmasını rahat bir çalışma pozisyonu elde etmek için yeterli gördüklerini, \%45'inin daha iyi çalışma pozisyonu için bir ayak desteğine ihtiyaç duyduklarını, cerrahların dörtte birinin bazı uygulamalar için masa yüzeylerini çok dar/çok geniş bulduklarını ve hastanın doğru konumlandırılmasında zorluk yaşadıklarını rapor edilmişlerdir (5). Araştırmacılar ayrıca, ameliyathanelerin \%83'ünde ekipman kablolarının tökezleme tehlikesi yarattığını, cerrahların çoğunun (\%79) ameliyat sırasında bu kabloların üzerine bastığını ve kabloların çalışmalarını engellediğini hissettiklerini (\%53) saptamışlardır (5).

\section{Ameliyathanede Karşılaşılan Bilişsel Ergonomik Risk Faktörleri}

Ergonomi sadece iş ortamının, çalışanların iş yapış şekillerine göre uyumlaştırılması süreci olarak düşünülmemelidir. Kişilerin psikolojik ve fizyolojik doyum düzeyleri, çalışma çevresiyle olan teması, araç-gereç kullanım yeterlilikleri gibi değişkenlerin, insan faktörleri ile olan etkileşimlerinin hasta memnuniyeti ve güvenliği üzerine olan etkilerini de görmeyi gerektirmektedir (1). Eğitim programlarını geliştirme, araç ve teknolojilerin tasarımı ve değerlendirilmesi, zaman baskısı altında karar verme, zihinsel iş yükü, kullanıcılara geribildirim sağlama, insan sistem tasarımıyla ilişkili beceri kazandırma bilişsel ergonomiyi kapsamaktadır $(1,2,4)$.

Ameliyathanede, yüksek zihinsel iş yükü, iş stresi, iletişim eksikliği, şiddet, fiziksel zorlanma, ağrı, yorgunluk, cerrahi kompli- 
kasyonlar, gecikmeler, insanın dayanıklılığı, iş memnuniyetsizliği, hemşireler arası tutarsızlık, işi bitirmek için sınırlı zaman, meslektaş ve yönetici desteği, insan-bilgisayar etkileşimi ve karar vermede yetersizlik bilişsel ergonomik risk faktörlerini oluşturmaktadır (3). Abdullahzade ve ark. (2016) ameliyathane hemşirelerinin yaptıkları işlemlerde doğru ergonomik yöntemler hakkında eğitim ve uygulama gereksinimi olduklarını saptanmışlardır (10). Sheikhzadeh ve ark. (2009) cerrahi ortamda hemşireler ve teknisyenlerin ergonomik risk faktörlerini algılama durumlarını inceledikleri çalışmada; dolaşıcı ve steril hemşirelerin, ameliyathaneyi; zorlayıcı, stresli ve karmaşık bir çalışma ortamı olarak algıladıkları ve kas iskelet sistemi rahatsızlığıyla sonuçlanan yorucu fiziksel çalışma faaliyetlerinin olduğu belirtilmektedir (14).

\section{Ameliyathanede Karşılaşılan Örgütsel Ergonomik Risk Faktörleri}

İletişim, ekip kaynak yönetimi, çalışma saatlerinin belirlenmesi, ekip çalışması, iş birliği içinde uyumlu çalışma, kalite yönetimi, güvenlik kültürü vb. örgütsel ergonominin konusudur $(1,2,4)$. Ameliyathanede, uzun çalışma saatleri, vardiya arası zaman azlığı, hastayken izin gününde veya hafta sonu çalışma, zorunlu fazla mesai, insan kaynakları yönetimi, iş ve çalışma saatlerinin organizasyonu, ekip çalışması, iş birliği ve kalite yönetimi örgütsel ergonomik risk faktörlerini oluşturmaktadır (3).

\section{Ergonomik Risklerin Sağlık Üzerine Etkisi}

Ameliyathane çalışanları iş ile ilgili kas-iskelet bozukluklarına neden olabilen ergonomik risk faktörlerine maruz kalmaktadır (6). Çalışma ortamının ergonomik olarak düzenlenmesi önemlidir, çünkü uygun olmayan yetersiz ergonomik tasarım, çalışanlarda incinme, stres ve yorgunluk gibi problemlere neden olmaktadır. Aynı zamanda çalışan verimliliği azalarak istenilen düzeyde kaliteli bir bakım hizmeti verilmesini de engellemekte ve hasta güvenliğini olumsuz yönde etkileyebilmektedir (1).

Ameliyathaneler cerrahi ekip için yüksek fiziksel ve bilişsel iş yükü oluşturabilen karmaşı bir ortamdır (15). Tekrarlayan hareketler, güç uygulama, uygun olmayan postür, uzun süre aynı pozisyonda kalma ve titreşim gibi işle ilgili fiziksel risk faktörleri ve iş memnuniyetsizliği, monoton iş, zaman baskısı, yetersiz iş arkadaşı desteği, dinlenme molalarının eksikliği gibi psikososyal risk faktörleri kas iskelet sistemi rahatsızlığına neden olabilmektedir (16).

Kas-iskelet sistemi rahatsızlıkları, tüm dünyada önemli bir meslek hastalığı olarak kabul edilmekte ve işle ilgili yaralanmalar ve sakatlikların ana nedenlerini oluşturmaktadır $(9,17)$. Ameliyathanede yapilan eylemler ergono-mik yapılmazsa bel ve sırt ağrilarına yol açar (6). Ameliyathanede, İBKİSH açısından risk taşıyan uygulamalar arasında; hastanın sedye- ameliyat masası arasında transferi, gövde ve boynun fleksiyonu, ameliyat yatağında hastaya pozisyon verilmesi, deri hazırlığı için baş, kol ve bacakların kaldırılması, uzun süre ayakta kalma, tekrarlayan hareketler, aletlerin taşınması ve kaldırılması ve aletlerin çekilmesi/itilmesi yer almaktadır $(7,9,17$ 19).

Uzun süreli ayakta kalma sonucu kan akış1 sinırlanır, kaslarda yorgunluk ve zedelenmeler oluşur (14,20-22). Düşen bir hastayı tutma çabası, her vardiyada 20'nin üzerinde kaldırma işi, tek başına kaldırma da kas, tendon, eklem ve ligamentlerdeki zedelenmeyi artırmaktadır (4). Fırçalanmış ekip üyeleri genellikle ayakta durma ve oturma arasında değişime giremeyecekleri için uzun süre ayakta kalmaya bağlı İBKİSH riski daha yüksektir (23).

El Ata ve ark. (2016) tarafindan ameliyathane hemşirelerinde İBKISH saptanması amacıyla yapılan çalışmada etkilenen bölgelerin sirasiyla; bel (\%76.1), dizler (\%67.9), omuz/kol (\%60.9), ayak bilekleri/ayaklar (\%60.9), boyun (\% $57.1)$, bilekler ve eller $(\% 52.2)$, kalçalar $(\% 46.7)$, omuz (\%37), dirsek (\%23.9) bölgeleri olduğu belirtilmiştir (9). Voss ve ark. (2017) cerrahların \%27.6'sının mesleki yaralanma bildirdiklerini, en yaygın olarak; servikal omurga ağrısı (\% 37.9), kas-iskelet yorgunluğu (\%36.2), vertebral disk yaralanmas1 (\%22.4), genel ağr1 (\%17.2), periferalnöropati (\%12.1), karpal tünel sendromu $(\% 10.3)$ ve tendonit $(\% 8.6)$ olduğunu belirtmişlerdir (11).

Açık, laparoskopik ya da mikrocerrahi gibi her bir ameliyat türünde ergonomik risk faktörleri vardır. Laparoskopik cerrahide bileklerin tekrarlayan hareketi, mikro cerrahide boyun statik postürü kas-iskelet bozukluklarına neden olabilir (17). Janki ve ark. (2017) tarafından laparoskopik cerrahide ergonomiyi inceledikleri çalışmada, 
cerrahların \%47.5'inin kas-iskelet sistemi sorunları yaşadığ 1 ve \%17.4'ünde sürekli olduğu belirlenmiştir. Minimal invaziv cerrahi, hastalar açısından yararlı olmasına rağmen, statik pozisyonda uzun süre kalma, monitöre bakma, kamera konumunu optimize etmek için kol ve omuzları siklıkla rahatsız konumlandırma ve ameliyat alanında hareketleri en aza indirgeme gibi dezavantajlarla hareket özgürlüğü daha kısitl olduğundan İBKİSH yaşanmaktadır (24). Laparoskopik cerrahide steril hemşirenin, çoğu zaman monitörü net bir şekilde görmesinin mümkün olmadığı, monitör yerleşiminde çoğunlukla cerrahın rahatlığına odaklanıldığı ve yanlış monitör yerleşimi ve pozisyonundan dolayı hemşirenin boyun, sirt ve üst ekstremitelerde İBKİSH riski olduğu belirtilmektedir (6).

Aghilinejad ve ark.'nın (2016) açık, laparoskopik ve mikrocerrahi ameliyatlarda cerrahlarda ergonomik risk faktörleri ve kas iskelet sistemi semptomlarını inceledikleri çalışmada; ameliyat türü ile cerrahların kas iskelet sistemi semptomları prevalansı arasinda anlamlı fark bulunmamıştır. Üç tür cerrahide de (açık cerrahi, laparoskopik ve mikrocerrahi) cerrahların kasiskelet sistemi semptom prevalansının yüksek olduğu (\%75'in üzerinde), belirtilerin boyun, bel ve ellerde daha yaygın olduğu bulunmuştur (17). Cerrahlar arasında farklı ameliyat tekniklerine göre kas iskelet sistemi rahatsızlıklarının lokalizasyonu veya şikayetlerin sıklığ fark olmadığı saptanmıştır (24).

Yüksek bilişsel ve fiziksel iş yüklerinin giderek artmasının, kariyer ömrünü etkileyebileceği belirtilmektedir (15). Kas iskelet sistemi hastalıkları, çalışanın ağrı ve yorgunluk yaşaması nedeniyle; iş doyumunu etkileyebilmekte, üretkenlik ve dikkatinin azalmasına, hata yapma ve yaralanma oranının artmasına, iş gücü kaybına, tükenmişliğe ve tıbbi hatalara neden olabilmektedir $(10,15,18,19,25,26)$. Yu ve ark.(2016) tarafindan yapılan çalışmada; altı yıl ve üzerinde çalışma süresi, gece vardiyasının birden fazla olması, haftada 40 saat ve üzeri çalışma süresi, zayıf sağlık durumu ve yorgunluk duygusunun İBKİSH prevalansı ile ilişkili olduğu belirlenmiştir (15). Vardiyalı çalışan hemşirelerin tükenmişlik, duygusal istikrarsızlık ve duygusal tükenmeye daha eğilimli oldukları ve daha az kişisel başarı hissine sahip oldukları belirtilmektedir. Vardiyalı çalışma ile kas iskelet sistemi hastalıkları arasında anlamlı ilişki bulunmuştur (9). Kas-iskelet sistemi yaralanmas1 olan cerrahların, non-steroid antiinflamatuvar ilaçlar ve kas gevşeticiler gibi daha fazla analjezik ve/veya masaja veya fizik tedaviye ihtiyaç duydukları, şikâyetlerin bazen rapor alınmasına (hastalık izni) hatta cerrahi görevlerin geçici olarak bırakılmasına neden olabildiği belirtilmektedir (24). Sheikhzadeh ve ark. (2009) cerrahi ortamda hemşirelerin ve teknisyenlerin ergonomik risk faktörlerini algılama durumlarını inceledikleri çalışmalarında; hemşire ve teknisyenler arasında İBKİSH prevalansinın yüksek olduğu ve bel ağrısı bunu takiben ayak bileği/diz ağrılarının işe devamsızlığın başlıca nedenleri olduğu tespit edilmiştir (14).

İyi tasarlanmamış ameliyathane araçları/cihazları (özellikle laparoskopik cerrahi ile ilişkili araçlar), etkin olmayan ameliyathane dizaynı ve cerrahın postürünün: yorgunluğa, rahatsızlığa ve ağriya sebep olduğu belirtilmektedir. Ayrıca kötü tasarlanmış aletlerden dolayı yorgunluğun artmas1, tıbbi hataların ve hasta zararlarının nedeni olabileceği belirtilmektedir (25). Alexandre ve ark. (2017) ameliyathanelerde giyilen kurşun önlüklerin sırt ağrısına ve yorgunluğa sebep olduğunu saptamışlardır (27).

İBKİSH oluşumuna neden olan durumlar ve bu durumlardaki değişim Kişisel Anket Yöntemleri (Öznel değerlendirmeler), Sistematik Gözlemlere Dayalı Yöntemler, Direkt ölçüm yöntemleri ile değerlendirilmelidir. Direkt ölçüm yöntemlerinin gözlemlerden, gözlemlerin ise kişisel anket yöntemlerinden daha iyi olduğu belirtilmektedir (28).

\section{Ergonomik Risklerden Korunma Önerileri}

Çalışma ortamında ergonomik tasarımların, çalışanların memnuniyetini artıracağı, işe bağlılıklarını pekiştireceği hasta ve çalışanlara daha güvenli ve kaliteli sağlık hizmeti sunma anlayışı kazandıracağı vurgulanmaktadır (1). İşyerlerinde iş sağlığı ve güvenliği mevzuatına uygunluğun sağlanması ve çalışanların korunmas1 olması gereken ilk adımdır. Mevcut kontrollerin etkinliği gözden geçirilmeli, bu risklere karş1 alınacak önlemler belirlenmeli ve gerekli iyileştirmeler yapılmalıdır (5). Çalışanların ihtiyaçlarının, isteklerinin ve görevleri nasıl yaptıklarının bilinmesi, hataları azaltmak ve daha iyi tıbbi cihazlar tasarlamak için önemlidir. Bu bilgiler, çeşitli değerlendirme yöntemleri (gözlemler, 
anketler, mülakatlar, kontrol listeleri, uzman değerlendirmeleri, kaza veya yaralanma analizleri, görev analizleri, güvenlik analizleri vb.) kullanılarak elde edilebilir (25).

Sağlık kurumlarında fiziksel, bilişsel ve kurumsal ergonomik ilkelerin uygulanması kurumsal performansı artıracak avantajlar sağlayacaktır (1). Ameliyathane ortamının ve kullanılan araçların ergonomik düzeyde yapılanmasıyla; çalışanların memnuniyetini artıracağı, işe bağlılıklarını pekiştireceği, kurumsal performansın artacağı, oluşabilecek rahatsızlıkları ve sağlık sorunlarını azaltarak, hasta ve çalışan güvenliği için uygun ortam yaratacağ belirtilmektedir $(1,6)$.

Risk faktörleri için önlemlerin planlanmas1, önleme politikalarının ve stratejilerinin geliştirilmesi, gerekli kontrollerin yapılması ve risklerden kaynaklanan yaralanmaların sağlik kayıtlarının tutulması ile birlikte yapılmalıdır (3). Çalışma ortamında insan-makine uyumunu ve iş verimliliğini artırmak, yaralanma riskini azaltmak ve çalışanların sağlığını korumak için ergonomik rehberler kullanılması önerilmektedir (6).

\section{Fiziksel Ergonomik Risk Faktörlerine Yönelik Öneriler}

Ameliyathane ortamında karşılaşılan fiziksel ergonomik risk faktörlerine yönelik literatürde yer alan öneriler aşağıdaki gibidir $(3,6,7,11,18-20,22$ 24,26,29-37);

- Hasta transferi yaparken dengeli olunmas1, hastayı kaldırmak için tek başına değil, hasta kaldırma ekibinden ya da meslektaşlarından yardım alınması, yatağın karşı tarafına uzanılmamas1; rollbord, hava yardımlı veya mekanik transfer cihazı gibi hasta taşıma cihazlarının kullanılması; araç-gereç/hastayı kaldırırken/döndürürken omurganın düz tutulması, aşırı fleksiyon/ekstansiyondan kaçınılması, taşıyacak kişinin yüzü hastaya/kaldırılacak cisme dönük olması, kaldırılacak cismin/hastanın gövdeye mümkün olduğunca yakın tutulması ve kaldırılması,

- Çalışanların günlük kaldırma sayısının sınırlandırılması, kaldırma kurallarının iyi bilinmesi, sürekli eğilmek gibi çok tekrarlayan hareketlerden mümkün olduğunca kaçınılması, daha güvenli hareket etme, itme ve kaldırma teknikleri konusunda talimatların asılması, alet tepsilerinin toplam ağırlığının yaklaşı $11 \mathrm{Kg}$ (25 IB) ile sinırlandırılması,
- Ekipmanları itilmesi/çekilmesi sırasında mümkün olduğunca itme hareketinin kullanılması, itme işleminin sadece kollarla değil bütün vücutla yapılması,

- Daha iyi araçların ve cerrahi tekniklerin tasarlanmas1, ayarlanabilir bir ameliyat masasının kullanılması (tabandan $29 \mathrm{~cm}$ ile $122 \mathrm{~cm}$ arasında ayarlanabilme özelliğine sahip masaların kullanılması),

- İki saatten fazla ya da çalışma saatinin \%30'undan fazlası uzun süre ayakta durmayı gerektiriyorsa; statik duruşun risklerini azaltmak için; steril alanda kullanılabilen istenilen yüksekliğe ayarlanabilen ergonomik taburelerin kullanılması, üst ekstremite ve bacak desteklerinin kullanılması, yorgunluk önleyici paspas kullanılması, destekleyici ayakkab1 giyilmesi ve ayak taburesi kullanılması, optimum çalışma yüksekliğinde ve postüründe olmaya dikkat edilmesi ve bu konuda talimatlar asılması, dolaşıcı ve steril hemşire rotasyonunun yapılması,

- Destekleyici ayakkabı giyilmesi, uzun süre ayakta durmanın olumsuz etkilerini azaltabilir. Ayağa iyi oturan ve destekleyen ortopedik ayakkabilar giyilmeli, önü kapalı ve parmakların hareketine izin verecek genişlikte olmalı, tabanı şok emici ve esnek yapıda olmalı, topuk yüksekliği en az $5 \mathrm{~cm}$ olmalı,

- Çalışma postürünün değiştirilmesi, bir ayağın altına tabure koyarak tek ayağı yükseltme ve ayakları ara ara değiştirme gibi yorgunluğu azaltıcı tekniklerin kullanılması,

- Küçük ince ekranlı ve tavandan monte monitörlerin kullanılması, doğrudan personelin önünde ve göz seviyesinin biraz altında olmasının sağlanması, monitör yerleşimi çoğunlukla cerrahın konforu üzerine kurulu olduğundan, diğer çalışanlara optimum görüntü sağlamak için ek monitörlerin kullanılmas1,

- Kullanılmayan ve çalışma alanlarını daraltan malzemelerin kaldırılması, koridorların ve ara geçitlerin açık tutulması,

- Yere dökülen sıvıların hemen temizlenmesi, zeminin kuru tutulması ve zeminlerin kaymayan özellikte materyalle döşenmesi ve emici pedlerin kullanılmas1,

- Zemindeki seviye farkları ve çukurların giderilmesi, ekipman kablolarının uygun 
şekilde kapatılması (geniş bantla kapama ya da duvar kenarına yapıştırma)

- Yüksek bölgeye erişmek ve orada çalışma yürütmek için güvenlikli sabit/taşınabilir merdiven kullanılması,

- Yeterli aydınlatmanın ve optimum nem, 1s1, etkili havalandırmanın sağlanması,

- Bozuk alet ve arabaların onarılması, alet ve diğer cihazların ergonomik yönergelere göre seçilmesi (tek elle kullanıma izin veren, değiştirilebilir ayarları olan, düğmelere kolayca erişilebilen hem kuvvetli hem de hassas kavrama sağlayabilen, çeşitli rotasyonlarda rahatlikla tutulabilen, çalıştırmak için düşük miktarda güç gerektiren aletler),

- Kişi başı kurşun önlük giyme sayısının sinırlandirilmas1,

- Otomatik retraktörler bu mümkün değilse; künt retraktörler kullanılmalı, retraktörler mümkün olduğunca vücuda yakın tutulmalı ve tutan kişi uygun yükseklik ve postürde olmalı, kollar mümkün olduğunca dinlendirilmelidir.

- Hastaların ekstremitelerini ya da başını uzun süre kaldırıp tutmak için tutma aparatı bulunan ve ameliyat masasina monte edilen bir kol kullanılması önerilmektedir.

- Albayrak ve ark.'nın (2007) yeni tasarım ergonomik vücut destek cihazlarını kullandıkları çalışmalarında, ergonomik destek cihazlarının hem açık hem de minimal invaziv işlemler sırasında cerrahın doğal duruşunu desteklediği, vücudun desteklenmesinin kas aktivitesini azaltmada etkili olduğu, uzun vadede fiziksel şikayet ve rahatsızlığ 1 azaltabileceği ve ameliyathanenin mevcut düzenine kolayca adapte edilebileceği belirtilmiştir. Mao ve ark.'nın (2015), sağlık bakımı ve hasta güvenliği uygulamaları üzerine insan faktörlerinin ve ergonominin etkilerini inceledikleri çalışmada; insan faktörleri ve ergonomik müdahalelerin çalışanlar üzerinde olumlu bir etkisinin olduğu, yeni ergonomik ekipman satın alındıktan sonra kas-iskelet sistemi rahatsızlık oranlarının ve personel yaralanmalarının azaldığı, çalışan sağlığının iyileştiğini gösteren kanıtların olduğu belirlenmiştir (38).

\section{Bilişsel Ergonomik Risk Faktörlerine Yönelik Öneriler}

Ameliyathane ortamında karşılaşılan bilişsel ergonomik risk faktörlerine yönelik;

- Hemşirelerin istihdam edilirken sağlıklı olma ve sağlığı koruma konusunda farkındalığının sağlanmas1,

- Hemşirelerin karar verme sürecine aktif katılımının sağlanması,

- Çatışmayı önlemek için ekip üyeleri arasında etkili iletişim sağlanması,

- Şiddetin önlenmesi,

- Çalışanların; yetkinliğini arttırma, kriz ve stres yönetimi, zaman yönetimi, doğru kaldırma, taşıma ve duruş kuralları, fiziksel aktivite/egzersiz programları konularında uzman kişilerden eğitim almas1 ve desteklenmesi önerilmektedir (3).

2004 yılında Alman Cerrahlar Derneği (Deutsche Gesellschaftfür Chirgurie) kongresinde, kongre katılımcıları ile görüşülmüş ve cerrahların \%60'ının ve ameliyathane hemşirelerinin \%40'inın tıbbi cihazların çalışması konusunda yeterince eğitilmedikleri ve az sayıda kişinin cihazların kullanım kılavuzlarını okudukları belirlenmiştir $(22,25)$. İyi bir ergonomik eğitim programı çalışanlara iş ekipmanlarını, aletlerini ve makinelarını en uygun şekilde nasıl kullanacaklarını ve işleri yapmak için en doğru yolları öğretecektir (21). Ameliyathanede cerrahi prosedürler sırasında cihaz kullanımı ile ilgili yetersiz eğitimin tıbbi hatalara neden olabileceği belirtilmektedir (25). Moazzami ve ark. (2016) ameliyathane hemşirelerinde doğru vücut yapısını kabullenmede Transtheoretical Modele göre ergonomiye dayalı eğitim uygulamasının etkisini inceledikleri çalışmada; eğitim alan gruptaki hemşirelerin büyük çoğunluğunun eylem aşamasına geçtiğ $i(p<0.05)$, öz-yeterlik puanlarının, doğru vücut duruşu puanının anlamlı derecede yüksek $(\mathrm{p}<0.05)$ olduğu saptanmıştır (8).

Kronik bel ağrısı için koruyucu stratejilerden biri, vücut mekaniğini ve duruşunu uygun bir biçimde öğretmektir. Çalışmalar, işyerinde yeterli vücut duruşunu korumak için ergonomi eğitiminin, hemşireler arasında işle ilgili kas-iskelet hastalıkları prevalansını azalttığını göstermiştir (8). Abdullahzade ve ark. (2016) tarafindan ameliyathane hemşirelerinin çalışma pozisyonlarına iliş̧kin yapılan çalışmada; günlük 
egzersiz yapan hemşirelerin diğerlerine göre daha ergonomik duruş sergiledikleri belirlenmiştir (10). Kavitha ve Vinodhini'nin (2017) çalışmasında hemşirelere 8 haftalık kapsamlı bir ergonomi eğitim programı verilmiş ve ergonomik risk değerlendirme ölçeği (RULA- Rapid Upper Limb Assessment- Hizlı üst ekstremite değerlendirme) ile değerlendirilmiştir. Araştırma sonucunda hemşirelerde vücut postürünün düzelmesi ile kas iskelet sistemi ağrısının ve sıklığının azaldığ 1 saptanmıştır (39).

\section{Örgütsel Ergonomik Risk Faktörlerine Yönelik Öneriler}

Ameliyathane ortamında karşılaşılan örgütsel ergonomik risk faktörlerine yönelik;

-Ergonomik hasta taşıma ekipman ve cihazlarının seçilmesi,

-İş akışı ile ilgili sorunların saptanarak, ergonomik şekilde yeniden düzenlenmesi,

-Pozitif kurum yapısı ve kültürü sağlanması,

-Işe yeni alınan personelin oryantasyon eğitimi programına ergonomik tehlikeler ve kontrol yöntemlerinin dahil edilmesi,

-Hemşirelere makul çalışma saatleri, düzenli mola verme, yeterli personel ve herkes için standart çalışma saatleri sağlanması,

-Günlük işlemler ve sorunlar konusunda düzenli olarak çalışanlara danışılması,

-Güvenli kaldırma politika ve prosedürlerinin olmas1,

-Şikâyet ve öneri programı oluşturulması,

- Düzenli denetimler yapılarak alınan kontrol ve önleme tedbirlerinin uygulanıp uygulanmadığg 1 veya bir sorun olup olmadiğ 1 düzenli olarak saptanması önerilmektedir (3).

Ergonomik rahatsızlıkların önlenmesi için yürütülecek programlarda; meslek hastalığı ve iş kazası kayıtlarının tutulması, rahatsılık septomlarının erken tanınması ve raporlanması, çalışanların sistemli bir şekilde sağlık taramasından geçmesi ve sonuçların raporlanması, sınırlandırılmış işler gibi koruyucu hizmetlerin faaliyete sokulması ve çalışanlara periyodik eğitim programı sağlanması, çalışanların işyeri sağlık ekipleriyle iletişiminin sağlanması gibi unsurları kapsaması önerilmektedir (21). Ameliyathanede çalışma koşullarının ergonomik olarak iyileştirilmesi, motivasyonu ve iş doyumunu artıracak ve hemşirelerin stres, işe giriş, meslek hastalıkları ve iş kazalarını azaltacaktır (3). $\mathrm{Bu}$ açıdan ameliyathanedeki ergonomik risk faktör-lerinin açık bir şekilde tanımlanması, uygulanacak olası çözümlerin araştırılması, önleme politikaları ve stratejilerinin geliştirilmesi, sonuçların değerlendirilmesi ve ergonomik olarak uygun çalışma ortamlarının sağlanması personel güvenliği için önemlidir. Ameliyathanelerde belirli aralıklarla ergonomik risk faktörleri değerlendirilmeli ve gerekli iyileştirmeler yapılmalıdır.

\section{Kaynaklar}

1. Aydemir İ, Yenimahalleli Yaşar G. Ergonomik Tasarımın Sağlı Çalışanları ve Hasta Güvenliğine Etkisi [The Effects of Ergonomic Design on Health Professionals and Patient Safety]. Sağlık ve Hemşirelik Yönetimi Dergisi [Journal of Health and Nursing Management] 2016; 3(3):174-184.

2. International Ergonomics Association - IEA. Definition and Domains of Ergonomics. Available: http://www.iea.cc. Via the INTERNET. Accessed 2017 October 12.

3. Vural F, Sutsunbuloglu E. Ergonomics: an important factor in the operating room. Journal of Perioperative Practice 2016; 26:(7-8): 175179.

4. Babayiğit MA, Kurt M. Hastane Ergonomisi [Hospital Ergonomics]. İstanbul Med J, 2013; 14: 153-9.

5. Matern U, Koneczny S. Safety, hazards and ergonomics in the operating room. Surg Endosc 2007; 21: 1965-1969.

6. Choi SDA. Review of the Ergonomic Issues in the Laparoscopic Operating Room. Journal of Healthcare Engineering 2012; 3(4): 587-603.

7. Nelson A, Waters TR, Spratt DG, Petersen C, Hughes N. Development of the AORN Guidance Statement: Safe Patient Handling and Movement in the Perioperative Setting. 2007. Available: http://www.wrha.mb.ca/professionals/safety/fi les/SafePatientHandling/AORNGuidanceState ment.pdf.Viathe INTERNET. Accessed 2017 October 12.

8. Moazzami Z, Dehdari T, Taghdisi MH, Soltanian A. Effect of an Ergonomics-Based Educational Intervention Based on Transtheoretical Model in Adopting Correct Body Posture Among Operating Room Nurses. Global Journal of Health Science 2016; 8(7): 26-34. 
9. El Ata GA, El Desouky S, Manawil M, Khalifa E. Assessment of Work- related Musculoskeletal Symptoms in Operation Room Nurses. Current Science International 2016; 5(2): 215-222.

10. Abdollahzade F, Mohammadi F, Dianat I, Asghari E, Asghari-Jafarabadi M, Sokhanvar Z. Working posture and its predictors in hospital operating room nurses. Health Promot Perspect 2016; 6(1):17-22.

11. Voss RK, Chiang YJ, Cromwell KD, Urbauer DL, Lee JE, Cormier JN, et al. Do no harm, except to ourselves? A survey of symptoms and injuries in oncologic surgeons and pilot study of an intraoperative ergonomic intervention. $\mathbf{J}$ Am Coll Surg 2017; 224(1): 16-25.

12. Albayrak A, vanVeelen MA, Prins JF, Snijders CJ, de RidderH, Kazemier G. A newly designed ergonomic body support for surgeons. Surg Endosc 2007; 21: 1835-1840.

13. VantHullenaar CDP, Hermans B, Broeders IAMJ. Ergonomic assessment of the da Vinci console in robot-assisted surgery. Innov Surg Sci 2017; 2(2): 97-104

14. Sheikhzadeh A, Gore C, Zuckerman JD, Nordin M. Perioperating nurses and echnicians' perceptions of ergonomic risk factors in the surgical environment. Applied Ergonomics 2009; (40): 833-839.

15. Yu D, Lowndes B, Thiels C, Bingener J, Abdelrahman A, Lyons R, Hallbeck S. Quantifying Intraoperative Workloads Across the Surgical Team Roles: Room for Better Balance?. World J Surg 2016; 40:1565-1574.

16.Özcan E, Kesiktaş N. Mesleki Kas İskelet Hastalıklarından Korunma ve Ergonomi [Occupational Musculoskeletal Disease Prevention and Ergonomics]. İş Sağlığı ve Güvenliği Dergisi [Journal of Occupational Health and Safety] 2007; 34: 6-9.

17.Aghilinejad M, Ehsani AA, Talebi A, Koohpayehzadeh J, Dehghan N. Ergonomic risk factors and musculoskeletal symptoms in surgeons with three types of surgery: open, laparoscopic, and microsurgery. Med J Islam Repub Iran 2016; 30: 1232-1237.

18.Ogg MJ. Introduction to the safe patient handling and movement series, AORN Journal 2011; 93: 331-333.

19.TTB. Sağlık Çalışanlarının Ameliyathanede Karşılaştıkları Riskler ve Korunma Yolları
[Risks and Methods of Protection for Health Workers in the Operating Room]. Türk Tabipler Birliği Yayını. Hermes Tanıtım Ofset. 2014, Ankara.

20.Meijsen P, Knibbe HJJ. Prolonged Standing in the OR: A Dutch Research study. AORN Journal 2007; 86: 399-414.

21.Ayanoğlu C. İş yerinde ergonomi ve stres [Ergonomics and stress at work]. İş Sağlığı ve Güvenliği Dergisi [Journal of Occupational Health and Safety] 2007; 34(7): 29-36.

22.Lowndes BR, Hallbeck Ms. Overview of Human Factors and Ergonomics in the OR, with an Emphasis on Minimally Invasive Surgeries. Human Factors and Ergonomics in Manufacturing \& Service Industries 2014; 24 (3): 308-317.

23.Hughes NL, Nelson A, Matz MW, Lloyd J. AORN Ergonomic Tool 4: Solutions for prolonged standing in perioperative settings. AORN Journal 2011; 93: 767-774.

24.Janki S, Mulder EEAP, IJzermans JNM, Tran TCK. Ergonomics in the operating room. Surg Endosc 2017; 31: 2457-2466.

25.Hallbeck MS, Koneczny S, Büchel D, Matern U. Ergonomic Usability Testing of Operating Room Devices. Stud Health Technol Inform 2008;132:147-52.

26.Brogmus G, leone W, butler L, hernandez E, Best Practices in OR Suite Layoutand Equipment Choices to Reduce Slips, Trips and Falls. AORN journal 2007; 86(3); 384-398.

27.Alexandre D, Prieto M, Beaumont F, Taiar R, Polidori G. Wearing lead aprons in surgical operating rooms: ergonomic injuries evidenced by infrared thermography. Journal of Surgical Research 2017; 209: 227-233.

28.Özel E, Çetik O. Mesleki Görevlerin Ergonomik Analizinde Kullanılan Araçlar ve Bir Uygulama Örneği [Tools Used in Ergonomic Analysis of Professional Tasks and An Application Example]. Dumlupınar Üniversitesi Fen Bilimleri Enstitüsü Dergisi [Dumlupınar University Science Institute Journal] 2010; Ağustos(22): 41-56.

29. Waters T, Baptiste A, Short M, Plante-Mallon L, Nelson A. AORN ErgonomicTool 1: Lateral transfer of a patient from a stretcher to an OR bed. AORN Journal 2011; 93(3): 334-339.

30. Waters T, Short M, Lloyd J, Baptiste A, Butler L, Petersen C, Nelson A. AORN Ergonomic 
Tool 2: Positioning and repositioning the supine patient on the OR bed. AORN Journal 2011; 93(4): 445-449.

31.Waters T.,Spera P., Petersen C., Nelson A., Hernandez E., Applegarth S., AORN Ergonomic Tool 3: Lifting and holding the patient's legs, arms and head while prepping. AORN Journal 2011; 93(5): 589-592.

32.Spera P, Lloyd JD, Hernandez E, Hughes N, Petersen C, Nelson A, Spratt DG. AORN Ergonomic Tool 5: Tissue retraction in the perioperative setting. AORN Journal 2011; 94(1):54-58.

33. Waters T, Baptiste A, Short M, Plante-Mallon L, Nelson A. AORN Ergonomic Tool 6: Lifting and carrying supplies and equipment in the perioperative setting. AORN Journal 2011; 94(2): 173-179.

34.Waters T, Lloyd JD, Hernandez E, Nelson A. AORN Ergonomic Tool 7: Pushing, pulling, and moving equipment on wheels. AORN Journal 2011; 94(3):254-260.

35. Occupational Safety \& Health Administration OSHA. Ergonomics for the Prevention of Musculoskeletal Disorders: Guidelines for Nursing Homes, OSHA 2009. Available: https://www.osha.gov/ergonomics/guidelines/ nursinghome/final_nh_guidelines.pdf Via the INTERNET. Accessed 2017 October 13.

36. Akarsu H, Güzel M. Sağlık Sektöründe Tehlike ve Riskler [Hazards and Risks in Healthcare]. Çalışma ve Sosyal Güvenlik Eğitim ve Araştırma Merkezi Yayını [Publication of Labor and Social Security Training and Research Center] 2016, Ankara

37.Hughes AB. Implementing AORN Recommended Practicesfor a Safe Environment of Care. AORN Journal 2013; 98(2): 154-166.

38. Mao X, Jia P, Zhang L, Zhao P, Chen Y, Zhang M. An Evaluation of the Effects of Human Factors and Ergonomics on Health Care and Patient Safety Practices: A Systematic Review. PLoSONE 2015; 10(6): 1-19.

39. Kavitha S MOT, Vinodhini C. A Study to Determine the Effectiveness of Ergonomic Training on Body Posture and Musculoskeletal Disorder in Hospital Nurses. International Journal of Pharmaceutical and Clinical Research 2017; 9(7): 498-504. 